\title{
АКТУАЛЬНЫЕ ТРЕНДЫ LIFE SCIENCES В УСЛОВИЯХ РАЗВИТИЯ ЦИФРОВОЙ ЭКОНОМИКИ
}

Стажарова Д.М. ФГАОУ ВО «Национальный исследовательский университет ИТМО», г. Санкт-Петербург, Россия

В статье представлен анализ ключевых трендов развития сферы наук Life sciences на текущиий год. Данная сфера обладает потенцииалом развития и важностью своих разработок для всего человечества. Цифровизачия оказывает огромное влияние на все сопряженные науки в данном блоке, доказательство чего представлено в намей статье.

Ключевые слова: здравоохранение, рынок здравоохранения, life sciences, науки о жизни, биотехнологии, биоразработки, цифровизация, цифровая экономика, цифровизация в медицине.

Мировой рынок здравоохранения достиг 2014 млрд. долларов в 2018 году, увеличившись на 7,3\% с 2014 года и, как ожидается, вырастет на 8,9\% в среднем до 11 908,9 млрд. долларов к 2022 году [1]. Сектор наук о жизни (life sciences) представлен компаниями, занимающихся исследованиями и разработками, коммерциализацией и передачей технологий в сферах:

- биомедицинских технологий;

- биомедицинских устройств;

- биотехнологий;

- космецевтики;

- нутрицевтики;

- обработки пищевых продуктов;

- окружающей среды;

- технологий жизненных систем;

- фармацевтических препаратов.

Науки о жизни, как и любая другая область, оказывают значительное влияние на все эти отрасли, и это побуждает компании изменять методы разработки и коммерциализации своей продукции. На сегодняшний день компании ищут новые способы повышения эффективности, но при этом революционируют фармацевтическую цепочку поставок с использованием искусственного интеллекта. Тем не менее, существует одна вещь, необходимая для внесения изменений - это развитие партнерских отношений, которые будут инновационными, основанными на отношениях и создающими ценность для потенциальных клиентов (пациентов). Для достижения успеха компаниям необходимо быть в курсе последних изменений в тенденциях всей отрасли. В 
данном исследовании рассмотрим главные и ключевые тренды в текущем 2020 году.

1- Искусственный интеллект

Ожидается, что сектор биологических наук станет свидетелем значительного увеличения в 2020 году предприятий, извлекающих выгоду из новой волны технологических инноваций, обусловленных как искусственным интеллектом, так и машинным обучением.

Существует множество способов использования ИИ в сфере биологических наук, таких как:

a) ускоренная диагностика заболеваний;

b) исследования для новых продуктов;

c) разработка лекарств.

2- Партнерские клинические исследования с модернизацичей

Включение технологий в клинические исследования сделает их более эффективными и экономически рациональными. Кроме того, это поможет пациентам быть более последовательными при лечении. Например, приложения могут отправлять им напоминания (уведомления) при наступлении времени последующего приема лекарственных препаратов. С другой стороны, это поможет сохранить данные пациента.

3 - Технологии автоматизации бизнес-процессов, основанные на метафорическом программном обеспечении роботов (ботов) или работников искусственного интеллекта

Чтобы быть в курсе новых технологических разработок, компаниям, специализирующимся в области биологических наук, необходимо будет автоматизировать весь процесс работы, чтобы избежать задержек и расхождений.

\section{4 - Автоматизированное управление контентом}

Бумага была основным источником для документирования медицинских и биологических наук из-за аудита и нормативных требований. Но сейчас наблюдается тенденция к использованию автоматизированных систем управления контентом, поскольку они более конфиденциальны.

\section{5- Стандартизация}

После начала модернизации компаний своих приложений в прошлом году с целью внедрения новых технологий и повышения вовлеченности пациентов, в этом году ожидается, что предприятия в области life sciences перейдут к фазе стандартизации своей бизнес-модели.

\section{6 - Технология управления соответствием}

По мере того, как фирмы распространяют свой бизнес на новые рынки с новой целевой аудиторией по всему миру, ожидается, что в ближайшем будущем компании, работающие в области наук о жизни, будут все больше и больше использовать машины для унификации управления информацией процедура, которая приведет к дополнительной автоматизации их процессов глобального соответствия.

7- Интернет вещзей технологии 
Чтобы плыть по волне инноваций, компании, работающие в области наук о жизни, будут прилагать больше усилий для интеграции своих систем с новейшими технологиями Интернета вещей, такими как носимые медицинские устройства и системы удаленного мониторинга пациентов.

8- Контроль затрат

Ожидается, что снижение стоимости инновационных лекарств станет основным фактором экономической целесообразности деятельности компаний, специализирующихся в области биологических наук, - стратегии, которая побудит крупных игроков отрасли обратиться к технологиям, чтобы ускорить их процессы и оптимизировать рабочие процессы.

\section{9- Генная инженерия}

Ожидается, что в 2020 году и в последующие годы генная инженерия, основанная на технологических достижениях, окажет значительное влияние на бизнес в области наук о жизни и здравоохранения.

10- Дополненная реальность

В ближайшем будущем значительно расширится использование компаниями life sciences технологий дополненной реальности для ускорения процессов передачи знаний, которые жизненно необходимы для освоения ухода за пациентами.

Таким образом, науки о жизни, включающие огромный перечень передовых и приоритетных направлений для всего человечества, имеют ключевые тренды для своего будущего развития. Наука не стоит на месте, и изменения в одной научной сфере, молниеносно влекут изменения на остальные научные направления. Например, глобальная цифровизация оставила свой след и продолжает оказывать свое влияние абсолютно на все научные практики, в том числе на науки о жизни, перечисленные в данной статье.

\section{Список литературы}

1. Healthcare Global Market Opportunities And Strategies To 2022 [Электронный ресурс] // Research and markets. The worlds largest market research store. URL: https://www.researchandmarkets.com/reports/4787550/ healthcareglobal-market-opportunities-and?utm_source $=$ BW\&utm_medium $=$ PressRelease \&utm_code =qfcn4b\&utm_campaign $=1269595+-+$ The $+\% 2411.9+$ Trillion+Global+Healthcare+Market $\% 3 \mathrm{a}+\mathrm{Key}+$ Opportunities $+\% 26+$ Strategies $+(201$ 4-2022)\&utm_exec=joca220prd. (дата обращения: 28.03.2020).

2. 2020 US and global life sciences outlook [Электронный ресурс] // Deloitte. URL: https://www2.deloitte.com/us/en/pages/life-sciences-and-healthcare/articles/us-and-global-life-sciences-industry-trends-outlook.html обращения: 28.03.2020). 